\title{
Comparison of Ocular Lens Thickness of Type-2 Diabetic Retinopathy Patients with Non-diabetic Control, Measured by High Resolution Ultrasonography
}

\author{
Khalada Parvin Deepa, ${ }^{1}$ Nusrat Ghafoor, ${ }^{2}$ Nawshin Siraj, ${ }^{3}$ Md. Ziaul Haque, ${ }^{4}$ Md. Ubaidul Islam, ${ }^{5}$ Most. Razina Jubaida. ${ }^{6}$
}

\begin{abstract}
Background \& objective: The aim of this study was to verify whether the ocular lens of type-2 diabetic retinopathy patients was thicker (measured by high resolution Ultrasonography) than those of non-diabetic individuals. The study also evaluated the differences in lens thickness (LT) between right and left eyes of diabetic retinopathy patients, and the differences in LT between proliferative and background retinopathy cases.

Methods: This case-control study was conducted on 68 subjects (34 cases and 34 controls) aged 20-60 years in the Department of Radiology and Imaging, BIRDEM Hospital from March 2015 to February 2016. Adult patients suffering from type-2 diabetic retinopathy confirmed by slit-lamp examination were selected as cases, while apparently healthy subjects were taken as control. Patients with history of heart failure, ocular surgery, acute eye conditions, such as, conjunctivitis, scleritis, cataract or any other co-morbidities were excluded. Ocular mean lens thickness was measured by high resolution ultrasonography and was compared between case and control groups by Un-paired t-Test.

Results: The study showed that type 2 diabetic patients had significantly thicker lenses than their non-diabetic counterparts (in right eye:case $4.1 \pm 0.3 \mathrm{~mm}$ versus control $3.7 \pm 0.1 \mathrm{~mm}, \mathrm{p}<0.001$ and in left eye:case $4.2 \pm 0.3 \mathrm{~mm}$ vs. control $3.7 \pm 0.1 \mathrm{~mm}, \mathrm{p}<0.001$ ). The study also revealed that proliferative retinopathy cases had thicker lenses than any other diabetic retinopathy groups $(p<0.05)$ and there was also statistically significant difference of $\mathrm{HbA} 1 \mathrm{c}$ level between proliferative and background type II diabetic retinopathy cases $(p<0.05)$

Conclusion: The study concluded that lens thickness is increased in type-2 diabetic retinopathy patients than that in non-diabetic healthy controls. The proliferative diabetic retinopathy cases possess thicker lens than the background retinopathy cases.
\end{abstract}

Key words: Lens thickness, type-2 DM, diabetic retinopathy, non-diabetic healthy control, high resolution ultrasonography etc.

\section{INTRODUCTION}

Diabetes mellitus (DM) is a leading cause of death and disability worldwide. ${ }^{1}$ Global prevalence of diabetes was about $8 \%$ in 2011 and is predicted to rise to $10 \%$ by 2030 . Nearly $80 \%$ of people with diabetes live in low and middle-income countries. ${ }^{2}$ The International Diabetes Federation in a metaanalysis showed that the prevalence of diabetes among adult population of Bangladesh had

\section{Authors' information: \\ ${ }^{1}$ Dr. Khalada Parvin Deepa, Specialist, Department of Radiology \& Imaging, Ibrahim Cardiac Hospital \& Research Institute. Dhaka, Bangladesh. \\ ${ }^{2}$ Dr. Nusrat Ghafoor, Associate Professor \& Consultant, Department of Radiology \& Imaging, Ibrahim Cardiac Hospital \& Research Institute. Dhaka, Bangladesh.}

${ }^{3}$ Dr. Nawshin Siraj, Associate Professor \& Senior Consultant \& Head of Department of Radiology \& Imaging. Ibrahim Cardiac Hospital \& Research Institute. Dhaka, Bangladesh.

${ }^{4}$ Dr. Md. Ziaul Haque, Consultant Radiologist, United Lincolnshire Hospital NHS Trust, Radiology Department PilgrimHospital, Sibsey Road, Boston, Lincolnshire, UK.

${ }^{5}$ Dr. Md. Ubaidul Islam, Specialist, Department of Radiology \& Imaging, 250-bedded Hospital, Moulvibazar, Bangladesh.

${ }^{6}$ Most. Razina Jubaida, Specialist, Asgarali Hospital, Dhaka, Bangladesh.

Correspondence: Dr. Khalada Parvin Deepa, Phone-01673640085, Email:khaladadeepa@gmail.com. 
increased substantially from $4 \%$ in $1995-2000$ to $9 \%$ in 2006-2010. The Federation estimated that about 7.1 million people have been diagnosed as diabetic in Bangladesh and almost an equal number remains undetected. ${ }^{3}$

Diabetic retinopathy is an ocular manifestation of DM, a systemic disease, which affects up to 80 percent of all patients who have had DM for 20 years or more. ${ }^{4}$ Diabetic retinopathy affects blood vessels in the light-sensitive tissue, called retina that lies in the back of the eye. It is the most common cause of vision loss among people with diabetes $^{5}$ resulting from microvascular retinal changes. Hyperglycemia-induced intramural pericyte death and thickening of the basement membrane lead to incompetence of the vascular walls. ${ }^{6}$ Diabetic retinopathy may progress through four stages: mild non-proliferative/background retinopathy, moderate non-proliferative/background retinopathy, severe non-proliferative/background retinopathy and proliferative diabetic retinopathy. ${ }^{7}$

The normal human eye appears as a circular hypoechoic structure when imaged with the help of a high-resolution B-scan ultrasound probes (ranging from 7.5 to $50 \mathrm{MHz}$ ). The normal lens is an anechoic structure, bounded anteriorly and posteriorly by anterior and posterior capsules, which appear as thin echogenic lines. ${ }^{8}$ So high-resolution B-scan ultrasound probes are used for higher quality imaging of the ocular anterior segment and have proven to be useful in detecting many pathologies, including lesions of the iris and ciliary body, sulcus-to-sulcus measurements, angle measurements, and imaging lenses (Fig. 1). ${ }^{9,10,11}$ In adult life normal mean lens thickness (MLT) is $3.16-3.76 \mathrm{~mm}$ with relatively little change in equatorial diameter. Since the eye is a fluid-filled structure, it provides a perfect acoustic window for USG, producing images with excellent detail. Ocular biometry by USG has been considered to be more precise and reliable than optical measurement. Therefore, it has been considered as a reference standard for the in vivo biometric measurement of the human lens. ${ }^{12}$
Fledelius and Miyamoto in a previous study reported a thicker lens in diabetics than in non-diabetics, and the lens thickness of diabetic retinopathy cases correlates with duration of diabetes. ${ }^{13}$

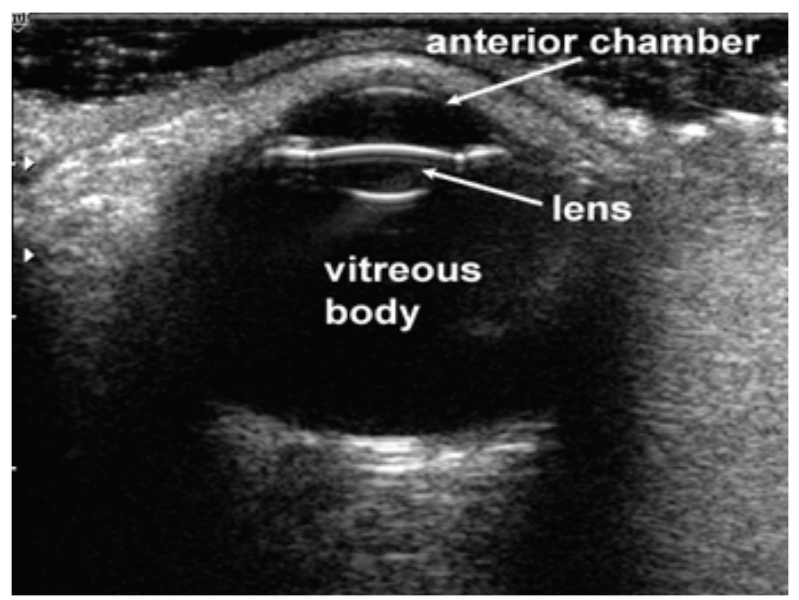

Fig 1. - Ultrasound anatomy of eye (Source: bediet al ${ }^{9}$ )

To the best of our knowledge, there are no available studies evaluating lens thickness in diabetic patients in Bangladesh by using high resolution USG. The present study, therefore examined the lens thickness in type-2 diabetic retinopathy patients and non-diabetic healthy controls and made a comparative evaluation of the lens thicknesses between diabetic retinopathy patients and non-diabetic individuals measured by high resolution ultrasonography.

\section{METHODS:}

This case-control study was attempted in the Department of Radiology and Imaging, BIRDEM Hospital from March 2015 to February 2016. Adult patients (aged 20-60 years) suffering from type-2 diabetes with retinopathy confirmed by slit-lamp examination were selected as case $(n=34)$, while apparently healthy adult subjects were included as control $(n=34)$. Patients with history of any ocular surgery, acute eye condition, as conjunctivitis, scleritis, cataract and type-2 diabetic retinopathy patients with any other co-morbidities and heart failure were excluded from the study. The equipments used for this 
study were Aloka prosound-6 \& Hitachi Aloka f 37 machine with a multi-frequency linear transducer of $7.5 \mathrm{mhz}$. B-Mode ultrasonography examination was performed with patients in supine position. Patients were scanned through closed eye, applying small amount of sonographic gel to the probe. The probe was positioned gently on the eyelid in the transverse projection. Depth was reduced to include the posterior aspect of the lens and was zoomed in to fill the screen. The lens was kept in center of screen. Maximum lens thickness was measured in mid-point of lens from anterior capsule to posterior capsule.

Data were analyzed by SPSS (Statistical Package for Social Sciences), versions 17.0 and test statistics used to analyze the data were descriptive statistics (mean and SD from the mean) and Unpaired t-Test. Unpaired t-Test was used to compare the lens thickness between case and control groups. The level of significance was set at $5 \%$ and $p$-value $<0.05$ was considered statistically significant.

\section{RESULT:}

The mean age of the case group was $49.1 \pm 9.3$ years (range: 20-60 years), while that of the control group was $46.9 \pm 9.6$ years (range: $20-63$ years). No significant difference was observed between the two groups in terms of age ( $p=$ $0.346)$. In the case group $18(53 \%)$ were male and the rest were female with male to female being $11: 9$, while in control group, $20(59 \%)$ were male with male to female ratio being roughly $3: 2$. In case group hypertension was the major co-morbidity ( $44.1 \%)$. Nearly $45 \%$ of the patients were hypertensive, $20.6 \%$ dyslipidaemic and $11.8 \%$ had other co-morbidities (Table I). Among the case group $19(56 \%)$ were suffering from proliferative type and $15(44 \%)$ from background type of diabetic retinopathy (Fig 2).

The mean $\mathrm{HbA} 1 \mathrm{c}$ level in proliferative type was $9.6 \pm 0.5 \%$ (range: $8.9-10.2 \%$ ) \& that in background type was $7.7 \pm 0.3 \%$ (range: $7.1-8.2 \%$ ). There was statistically significant difference in HbA1c level between proliferative and background type of diabetic retinopathy ( $p<0.001$ ) (Table II). The MLT of right eye in control group was $3.7 \pm 0.1$ $\mathrm{mm}$ (range: $3.3-3.9 \mathrm{~mm}$ ), and that in type II diabetic retinopathy patients was $4.1 \pm 2.9 \mathrm{~mm}$ (range: 3.7-4.6 mm). The mean difference of lens thickness of right eye in the two groups was significantly different $(p<0.001)$. The lens of left eyes in case group was significantly thicker than that in the control group $(4.2 \pm 0.3$ vs. $3.7 \pm 0.1$ $\mathrm{mm}, \mathrm{p}<0.001$ ) (Table III). The mean lens thicknesses of right and left eyes in type II diabetic proliferative retinopathy patients were significantly greater than those in background type of retinopathy patients $(4.4 \pm 0.2 \mathrm{~mm}$ vs. 3.9 $\pm 0.1 \mathrm{~mm}, \mathrm{p}<0.001$ and $4.4 \pm 0.2 \mathrm{~mm}$ and 3.9 $\pm 0.2, p<0.001$ respectively) (Table IV).

\begin{tabular}{|lcc|}
\hline \multicolumn{3}{|c|}{ Table I. Distribution of the cases by presence of co-morbidities } \\
\hline Co-morbidity & Frequency & Percentage \\
\hline Hypertension & 15 & 44.1 \\
Dyslipidaemia & 7 & 20.6 \\
Others* & 4 & 11.8 \\
None & 8 & 23.5
\end{tabular}

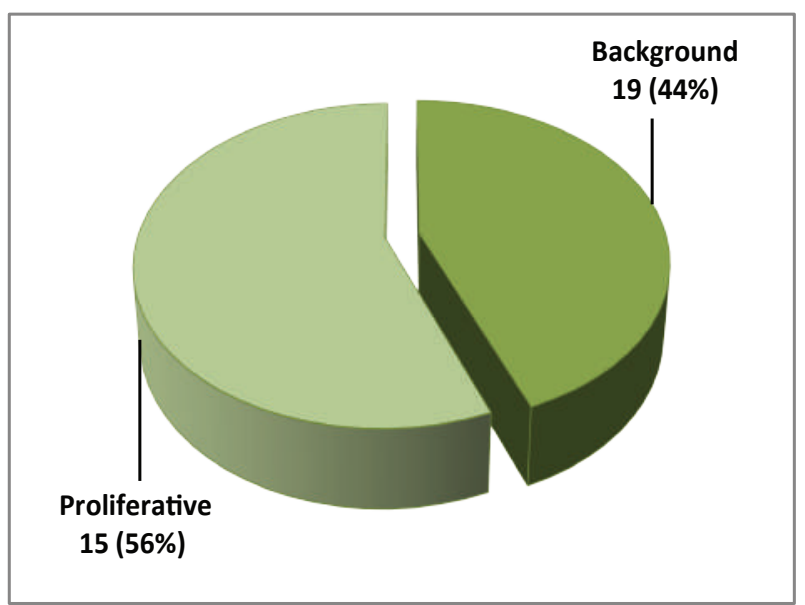

Fig 2: Pie diagram showing stages of diabetic retinopathy $(n=34)$

\begin{tabular}{|c|c|c|c|c|}
\hline $\mathrm{HbA1C}(\%)^{\#}$ & Mean \pm SD & Range & t-value* & p-value \\
\hline Proliferative type $(n=19)$ & $9.6 \pm 0.5$ & $8.9-10.2$ & \multirow{2}{*}{13.684} & \multirow{2}{*}{$<0.001$} \\
\hline Background type $(n=15)$ & $7.7 \pm 0.3$ & $7.1-8.2$ & & \\
\hline
\end{tabular}

\#Data were analyzed using Unpaired t-Test and were presented as Mean \pm SD. 


\begin{tabular}{|c|c|c|c|}
\hline \multicolumn{4}{|c|}{$\begin{array}{l}\text { Table III: Comparison of lens thickness ofeyes between case } \\
\text { and control groups }\end{array}$} \\
\hline \multirow[b]{2}{*}{ Lens thickness $(\mathrm{mm})^{\#}$} & \multicolumn{2}{|c|}{ Group } & \multirow[b]{2}{*}{$\mathrm{p}$-value } \\
\hline & $\begin{array}{l}\text { Case } \\
(n=34)\end{array}$ & $\begin{array}{l}\text { Control } \\
(\mathrm{n}=34)\end{array}$ & \\
\hline Right Eyes & $\begin{array}{l}4.1 \pm 2.9 \\
(3.7-4.6)\end{array}$ & $\begin{array}{c}3.7 \pm 1.3 \\
(3.3-3.9)\end{array}$ & $<0.001$ \\
\hline Left Eyes & $\begin{array}{l}4.2 \pm 0.3 \\
(3.8-4.8)\end{array}$ & $\begin{array}{l}3.7 \pm 0.1 \\
(3.4-3.9)\end{array}$ & $<0.001$ \\
\hline
\end{tabular}

\#Data were analyzed using Unpaired t-Test and were presented asmean \pm SD. Values in the parentheses denote range.

\begin{tabular}{|c|c|c|c|}
\hline \multirow[b]{2}{*}{ Lens thickness $(\mathrm{mm})^{\#}$} & \multicolumn{2}{|c|}{ Types of Retinopathy } & \multirow[b]{2}{*}{$p$-value } \\
\hline & $\begin{array}{l}\text { Proliferative } \\
(n=19)\end{array}$ & $\begin{array}{l}\text { Background } \\
(\mathrm{n}=15)\end{array}$ & \\
\hline Right Eyes & $4.4 \pm 0.2$ & $3.9 \pm 0.1$ & $<0.001$ \\
\hline Left Eyes & $4.4 \pm 0.2$ & $3.9 \pm 0.2$ & $<0.001$ \\
\hline
\end{tabular}

\#Data were analyzed using Unpaired t-Test and were presented Bstmearsisso.N:

The aim of this study was to verify whether the ocular lens of type-2 diabetic retinopathy patients was thicker than those of non-diabetic individuals measured by high resolution USG. In our study the lens was shown to be thicker in the diabetic retinopathy patients compared to that the non-diabetic healthy individuals had ( $p<0.001)$. In a subset of case group analysis only, the proliferative retinopathy cases appear to have thicker lens than the background retinopathy groups in both right and left eyes ( $p<0.001)$. A previous ultrasound study has reported a thicker lens in diabetics than in non-diabetics, and the lens thickness of diabetic retinopathy cases was found to well-correlate with duration of diabetes. ${ }^{13}$ A study, where diabetic patients was divided into no retinopathy, background retinopathy, proliferative retinopathy and control. The lens thickness of these four groups was significantly hetrogeneous $(p<0.05)$. Significant differences persisted among them with highest thickness being in proliferative retinopathy even after adjusting for age and duration of diabetes ( $p<$ 0.05); The mean lens thicknesswas shown to correlate significantly with diabetes duration as well. ${ }^{14}$ Another study reported that the lenses type1 DM were generally thicker (3.86 $\pm 0.60 \mathrm{~mm})$ compared to those of a healthy control $(3.58 \pm 0.18$ $\mathrm{mm}$ ) of similar age ( $\mathrm{p}<0.05)$, whereas the lenses of type2 diabetic group were even more thicker (4.35 \pm $0.59 \mathrm{~mm}$ ) than those of their control counterpart of similar age $(p<0.05) .{ }^{15}$ indicating that lenses are more affected in type 2 diabetics than those in type 1 diabetics.

A population-based study conducted in Denmark demonstrated a statistically significant positive correlation between duration of IDDDM and lens thickness, as assessed by the twin control method $(r=0.58, p=0.018$ and $r=0.69, p=0.005$ for right and left eyes, respectively). ${ }^{16}$ On the other hand, regardless of the type of diabetic treatment, only diabetic retinopathy, apart from age, was a significant parameter affecting lens biometry in late onset diabetes. ${ }^{17}$ Age-related increases in axial lens thickness, cortical thickness and nuclear thickness are accelerated after the onset of diabetes. ${ }^{18}$ The expansion of the sagittal width of the lens is also accelerated in diabetic patients. ${ }^{18} \mathrm{~A}$ study of diabetic patients with controlled blood glucose reported no correlation between $\mathrm{HbA} 1 \mathrm{C}$ and $\mathrm{MLT}^{14}$ indicating that when diabetic treatment begins, and blood sugar is controlled, the lens resumes its normal thickness. ${ }^{19}$ In contrast, another study reported that FBS (fasting blood sugar), postprandial blood sugar, and HbA1C had no significant influence on lens thickness. ${ }^{20}$ In our study, among the diabetic patients, there was no significant difference between right and left MLTs, which bears consistency with the findings of Pierro et al. ${ }^{14}$ We used high resolution ultrasound biometry to measure lens thickness in our study, which is easily available, less expensive and non-invasive than other optical measurements. Other investigators used USG to evaluate lens thickness in diabetics also reported a positive correlation between glycemic status and lens thickness $(r=0.58, p=0.018$ and $r=0.69, p=0.005$ for right and left eyes, respectively). ${ }^{16}$ The limitation of the present study is that the correlation of lens thickness with different parameters of glycemic status, patients' age and duration of diabetes were not addressed. Besides, when sub-set analysis was done between background and proliferative retinopathy patients, the sample 
size was reduced to bare minimum, which might have affected the validity of the findings.

\section{CONCLUSION}

From the findings of present study it can be concluded that ocular lens thickness (measured by high resolution ultrasonography) is increased in type-2 diabetic patients with retinopathy than their non-diabetic counterparts. Therefore, routine ocular follow up by high resolution ultrasound is essential to help early detection of lenticular thickness changes which may predispose to cataract formation and its attendant risk of visual impairment. B-mode high resolution ultrasonography is a relatively cheap, available, painless and nonhazardous, non-invasive ocular imaging tool. It can be routinely used in type-II diabetic patients with retinopathy for lens thickness measurement which may help concerned physicians and ophthalmologists to take appropriate measures for treating and following up the patients for early diagnosis of ocular complications, which might have preventive implications.

\section{REFERENCE:}

1. Lozano R, Naghavi M, Foreman K, Lim S, Shibuya K, Aboyans V. Global and regional mortality from 235 causes of death for 20 age groups in 1990 and 2010: A systematic analysis for the Global Burden of Disease Study. Lancet 2012;380:2095-2128.

2. IDF diabetes atlas. Country Estimates Table 2011. 2012; International Diabetes Federation. 6th ed. Available at:http://www.idf.org/sites/default/files/EN_ 6E_Atlas_Full_0.pdf. on 27 September 2015.

3. Saquib N, Saquib J, Ahmed T, Khanam MA, Cullen MR. Cardiovascular diseases and type 2 diabetes in Bangladesh: a systematic review and meta-analysis of studies between 1995 and 2010. BMC Public Health 2012;12:434.

4. Kertes PJ, Johnson TM. ed. Evidence Based Eye Care. Lippincott Williams \& Wilkins. Philadelphia:2007.

5. Klein R, Klein BE, Moss SE, Davis MD, Demets DL. The Wisconsin epidemiologic study of diabetic retinopathy. Prevalence and risk of diabetic retinopathy when age and diagnosis is less than 30 years. Arch Ophthalmol $1984 ; 102: 520-526$.

6. Pardianto G. Understanding diabetic retinopathy. Mimbar Ilmiah Oftalmologi Indonesia 2;2005:65-66.
7. Bethesda MD. Facts about Diabetic Eye Disease. 2015;Available at: https://nei.nih.gov/health/diabetic/ retinopathy/ on 190ctober 2015.

8. Radiology Blog Spot. Ultrasound Image of A Normal Eye with Lens. 2014; Available at: http://onradiology. blogspot.co.uk/2011/05/ ultrasound-image-of-normaleye-with.html on 19 October 2015.

9. Bedi DG, Gombos DS, Ng CS, Singh S. Sonography of the Eye. Am J Rontgen 2006;187(4):1061-1072.

10. Waldron RG, Aaberg TM. B-Scan Ocular Ultrasound. 2014; Available at: http://emedicine.medscape.com/ article/1228865-overview on 190ctober 2015.

11. Silverman RH. High-resolution ultrasound imaging of the eye-a review. Clinical \& Experimental Ophthalmol 2009;37:54-67.

12. Zeng $Y$, Liu $Y$, Liu $X$, Chen C, Xia $Y$, Lu M, etal. Comparisonoflens thickness measurements using the anterior segment optical coherence tomography and A-scan ultrasonography. Invest Ophthalmol Vis Sci 2009;50:290-4.

13. Fledelius HC, Miyamoto K. Diabetic myopia - is it lens induced? an ocular study comprising ultrasound measurements. Acta Ophthalmol (Copenh) 1987;65: 469-473.

14. Pierro L, Brancato R, Zaganelli E, Guarisco L, Calori G. Correlation of lens thickness with blood glucose control in diabetes mellitus. Acta Ophthalmol Scand $1996 ; 74(6): 539-541$.

15. Raitelaitienè R, Paunksnis A, Ivanov L, Kurapkienè S. Ultrasonic and biochemical evaluation of human diabetic lens. Medicina 2005;41:641-8.

16. Løgstrup N, Sjølie AK, Kyvik KO, Green A. Lens thickness and insulin dependent diabetes mellitus: a population based twin study. $\mathrm{Br} J$ Ophthalmol 1996; 80:405-408.

17. Sparrow JM, Bron AJ, Brown NAP, Neil HAW. Auto fluorescence of the crystalline lens in early and late onset diabetes. $\mathrm{Br} J$ Ophthalmol 1992;76:25-31.

18. Sparrow JM, Bron AJ, Brown NAP, Neil HAW. Biometry of the crystalline lens in early-onset diabetes. $\mathrm{Br} \mathrm{J}$ Ophthalmol 1990;74:654-660.

19. Joslin Diabetes Centre. Diabetes information/diabetes resource. 2013 Available at: www.joslin.org/diabetesinformation. [Last accessed September 18, 2018].

20. Shrestha S, Kaini KR. The influence of diabetes mellitus on lenticular thickness. Am J Public Health Res 2015; 3:91-4. 